\title{
Novel single-domain antibodies against the EGFR domain III epitope exhibit the anti-tumor effect
}

\author{
Tao Chen ${ }^{\dagger}$, Xue Liu ${ }^{\dagger}$, Haifeng Hong and Henry Wei ${ }^{*}$
}

\begin{abstract}
Background: Monoclonal antibodies (mAbs) have been used for cancer therapy. They are large and have some disadvantages limiting their use. Smaller antibody fragments are needed as their alternatives. A fully human singledomain antibody ( $\mathrm{s} \mathrm{A} \mathrm{Ab}$ ) has a small size of only $15 \mathrm{kDa}$ and consists of only the variable domain of the human antibody heavy chain $(\mathrm{VH})$. It has no immunogenicity. It can easily penetrate into tumor tissues, target an epitope inaccessible to $\mathrm{mAb}$ and be manufactured in bacteria for a low cost. Epidermal growth factor receptor (EGFR) is overexpressed in many cancer cells and is a good target for cancer therapy.

Methods: The EGFR protein fragment located on the EGFR extracellular domain III was chosen to screen a human sdAb library. Five human anti-EGFR sdAbs were identified. Their specific binding to EGFR was confirmed by ELISA, Western blotting and flow cytometry. Their anti-tumor effects were tested.

Results: Five novel fully human anti-EGFR sdAbs were isolated. They specifically bound to EGFR, not to the seven unrelated proteins as negative controls. They also bound to the three different human cancer cell lines, but not to the two cell lines as negative controls. They inhibited cell proliferation, migration and invasion and increased apoptosis of these three cancer cell lines. Two of them were tested for their anti-tumor effect in vivo and showed the anti-tumor activity in a mouse xenograft model for human lung cancer. Immunohistochemical staining of xenograft tumors also showed that their anti-tumor effects were associated with the inhibition of cancer cell proliferation and the promotion of cancer cell apoptosis.
\end{abstract}

Conclusions: This study clearly demonstrated that the anti-EGFR sdAbs could inhibit cancer cell growth in vitro and tumor growth in vivo. They could be potential therapeutics for the treatment of different human cancers.

Keywords: EGFR, Cancer, Antibody, Single-domain antibody, Antibody phage library

\section{Background}

Epidermal growth factor receptor (EGFR) family comprises the four homologous members: EGFR or HER1, also known as ERBB1, HER2 or ERBB2, HER3 or ERBB3 and HER4 or ERBB4 [1]. Each member consists of an

\footnotetext{
*Correspondence: 2217260762@qq.com

${ }^{\dagger}$ Tao Chen and Xue Liu contributed equally to this work Department of Cell Biology and Institute of Biomedicine, National Engineering Research Center of Genetic Medicine, Guangdong Provincial Key Laboratory of Bioengineering Medicine, College of Life Science and Technology, Jinan University, Guangzhou 510632, Guangdong, China
}

extracellular domain (ECD), a transmembrane domain and an intracellular domain (ICD) [2]. EGFR contains an extracellular domain (EGFR-ECD) of 620 amino acids, a transmembrane domain of 23 amino acids and an intracellular domain (EGFR-ICD) of 501 amino acids. EGFRECD comprises four domains, and the domains I and III include EGF binding sites. The EGFR-ICD includes a tyrosine kinase site. After EGF binds to EGFR, EGFR dimmer is formed and induces intracellular tyrosine phosphorylation, leading to the activation of the EGF/ EGFR signaling pathway [3]. Studies indicate that the 
EGF/EGFR signaling pathway interacts with EGFR-ERK, EGFR-STAT3 and EGFR-mTOR signaling pathways [4]. These pathways are associated with tumor cell proliferation, vitality, migration and invasion. They are also associated with the angiogenesis in the tumor microenvironment, tumorigenesis and tumor progression and metastasis [5, 6]. According to the previous reports, EGFR and HER2 are expressed mostly at a low level in all normal cells, while HER3 and HER4 are expressed at a moderate to high level in all normal cells. EGFR overexpression in cancer cells is closely associated with poor clinical prognosis, reduced survival rate and more aggressive phenotype [7]. EGFR over-expression was shown in several solid tumors, such as lung, breast and prostate cancers [8-10]. Therefore, EGFR may serve as an attractive target for cancer therapy of different cancers [11].

Monoclonal antibodies (mAbs) have become powerful therapeutics for cancer therapy. Trastuzumab is an anti-EGFR mAb approved for the treatment of breast cancer. Cetuximab is another mAb targeting EGFR and was approved for the treatment of metastatic colorectal cancer, metastatic non-small cell lung cancer and head and neck cancer. However, mAbs used for cancer therapy have many disadvantages. Mouse-derived mAbs can result in rapid antibody clearance, loss of efficacy or hypersensitivity reactions in cancer patients [12]. Along with the development of genetic engineering, chimeric antibodies or humanized antibodies were developed and reduced only some of their antigenicity [13]. MAbs are difficult to penetrate into solid tumors due to their large molecular weight and expensive to be manufactured with mammalian cells $[14,15]$. Thus, small size antibodies are needed to replace the conventional mouse-derived mAbs for cancer therapy. Single-chain variable fragment $(\mathrm{scFv})$ is a small-size antibody of about $40 \mathrm{kDa}$, consisting of only the variable domains of the $\mathrm{mAb}$ heavy $(\mathrm{VH})$ and light chains (VL). For example, ScFv-1171 is a derivative of mAb panitumumab and can bind to HER1 and induced apoptosis in rhabdomyosarcoma cells [16]. Human single-domain antibody (sdAb) of about $15 \mathrm{kDa}$ consists of only the variable domain of human antibody heavy chain and has no immunogenicity $[17,18]$. It has good tissue and tumor penetration [19]. It can access an epitope inaccessible to the large-size conventional $\mathrm{mAb}$ $[20,21]$. Moreover, human sdAb can be easily manufactured in bacteria at a very low cost. Fully human sdAbs are less stable and soluble than the natural camelid heavy chain-only antibodies due to the lack of conserved framework region residues. Studies have significantly increased the $\mathrm{sdAb}$ stability and solubility by constructing synthetic human sdAb library from reference to the natural camelid heavy chain-only antibodies [22].
In this study, an EGFR protein fragment located at its extracellular domain was chosen for screening a fully human sdAb library. Five human anti-EGFR sdAbs were identified and tested for their effect on the three different cancer cell lines. Two of them were tested for their effect on a mouse cancer model. They showed potent anti-tumor activity in vitro and in vivo and can potentially become good candidates for the treatment of various cancers.

\section{Materials and methods \\ Reagents and cell culture}

Anti-M13-horseradish peroxidase conjugate (anti-M13HRP) was purchased from Sino Biological (Beijing, China). Protein A-HRP was purchased from Thermo Fisher (Waltham, MA, USA). Expression vector pET22b (+), E. coli DH5a and BL21 (DE3) were purchased from Novagen (EMD Millipore, Madison, WI, USA). Isopropyl- $\beta$-D-thiogalactopyranoside (IPTG), phenylmethylsulfonyl fluoride (PMSF) and annexin V/PI apoptosis detection kit were purchased from Sangon Biotech (Shanghai, China). Nickel nitrilotriacetic acid $\left(\mathrm{Ni}^{+}-\mathrm{NTA}\right)$ resin was purchased from Sevensea Biotech (Shanghai, China). Dimethyl sulfoxide (DMSO) and 3-(4,5-Dimethylthiazol-2-yl)-2,5 diphenyltetrazolium bromide (MTT) were purchased from Sigma Aldrich (St. Louis, MO, USA). Matrigel and transwell chambers were purchased from BD Biosciences (San Jose, CA, USA). Cis-platinum was purchased from the pharmacy of the first affiliated hospital of Jinan University (Guangzhou, China).

Human cancer cell lines (A549, DU145 and MCF-7) were purchased from American Type Culture Collection (ATCC, Manassas, VA, USA). A549 and DU145 cells were cultured in RPMI 1640 medium (Invitrogen, Carlsbad, CA, USA) supplemented with $10 \%$ fetal bovine serum (FBS, Invitrogen). MCF-7 cells were cultured in DMEM medium (Invitrogen) supplemented with 10\% FBS. Cells were cultured at $37{ }^{\circ} \mathrm{C}$ in a humidified incubator containing $5 \% \mathrm{CO}_{2}$.

\section{Screening for anti-EGFR sdAbs by phage display}

Human domain antibody library (DAb) was purchased from Source BioScience (Nottingham, UK). A single human V3-23/D47 VH framework was used for the construction of the fully human sdAb phage-display library with diversity introduced in the antigen-binding site. The diversified hypervariable region in complementarity determining region 1 (CDR 1), CDR 2 and CDR 3 included H27-H33, H35, H50, H52-H54, H94, H95H100 (a-k), H101 and H102. The library has $3 \times 10^{9}$ sdAb clones in an ampicillin resistance phagemid vector pR2 containing MYC and VSV tags. Phagemids were 
produced from E. coli TG1 and used for screening antiEGFR sdAbs.

Phage manipulation was performed as previously described [23]. Briefly, the E. coli sdAb library was infected by M13 helper phages. Phages were collected by $\mathrm{PEG} / \mathrm{NaCl}$ precipitation. Immuno MaxiSorb tubes (Nunc, Rochester, NY, USA) were coated with an EGFR protein fragment located in EGFR extracellular domain III at 100, 50, 50, 25 and $25 \mu \mathrm{g} / \mathrm{ml}$, respectively for the first, second, third, fourth and fifth round of screening. Phages in the sdAb library were incubated. After bound phages were eluted, TG1 was infected and cultured overnight. Colonies were scraped from the plates, and TG1 were infected with KM13 helper phages. Phages were concentrated by $\mathrm{PEG} / \mathrm{NaCl}$ precipitation and used for the next round of library screening.

\section{Polyclonal phage ELISA}

Phages derived from the library screening were checked using polyclonal phage ELISA. EGFR fragment $(0.2 \mu \mathrm{g} /$ well) or BSA as a control was used to coat wells of a 96-well plate at $4{ }^{\circ} \mathrm{C}$ overnight. After being blocked for $2 \mathrm{~h}$ at room temperature, phages from each round of screening were added to appropriate wells. Then, the anti-M13-HRP secondary antibody (Sino Biological, Shanghai, China) was added, and the plates were incubated. TMB (3, 3', 5, 5'-Tetramethylbenzidine) (Beyotime Institute of Biotechnology, Haimen, China) was added. The reaction was stopped with sulfuric acid after color development. Absorbance of each well was measured at $450 \mathrm{~nm}$ by an automated microplate reader (Bio-RAD 680, Bio-RAD, Hercules, CA, USA).

\section{Monoclonal phage ELISA}

After phages derived from the five rounds of screening were checked by the polyclonal phage-ELISA, E. coli TG1 was infected with phages from the fifth round of screening showing the highest absorbance. A total of 448 bacterial colonies were randomly picked and cultured in 96-well plates, and phage clones were derived from these bacterial clones by the infection of M13 helper phages.

For monoclonal phage ELISA, each well of 96-well plates was coated with EGFR protein fragment and blocked with $2 \%$ BSA. Eight unrelated antigens including VEGF, EndoF1, CampH, HER2, BMP2, SPB2, FGF21 and CXCR4 were included as negative controls. The plates were washed three times. The remaining steps are the same as polyclonal phage ELISA as described above. Each of these anti-EGFR sdAb clones was then sequenced, and different DNA sequences were identified by the comparison of all clones sequenced.

\section{Expression and purification of sdAbs}

To express and purify the anti-EGFR sdAbs, the clones were amplified by PCR and ligated into the expression vector pET22b $(+)$ (Novagen) using a forward primer (5'-GATCCATGGCCCAGGTGCAGCTGT-3') containing a NcoI site and a reverse primer (5'-TCTGCGGCC GCGCTCGAGAC-3') containing a NotI site. The recombinant plasmid was transformed into E. coli BL21 (DE3) (Novagen). Bacterium clones were randomly picked and incubated overnight at $37^{\circ} \mathrm{C}$ at $220 \mathrm{rpm}$ in $\mathrm{LB}$ medium containing ampicillin. IPTG (Sangon Biotech) was added. Culture medium was harvested, and bacterium pellet was resuspended in PBS containing PMSF (Sangon Biotech). Protein was dissolved after bacteria were broken down by the sonication. Soluble protein extract was obtained by centrifugation, and protein was purified by a $\mathrm{Ni}^{+}-\mathrm{NTA}$ resin column (Sevensea Biotech). Protein was examined by $15 \%$ SDS-PAGE, and protein concentration was determined by BCA kit (Sangon Biotech).

\section{ELISA assay with the purified anti-EGFR sdAbs}

Each well of 96-well plates was coated with the EGFR protein fragment or the seven unrelated antigens (VEGF, EndoF1, CampH, HER2, BMP2, FGF21 and CXCR4) as negative controls. Plates were washed, blocked and incubated with each of the five purified anti-EGFR sdAbs. The remaining steps are the same as polyclonal phage ELISA described above except anti-M13-HRP secondary antibody was replaced by protein A-HRP secondary antibody (Thermo Fisher).

\section{Western blotting}

EGFR complete extracellular domain protein was purchased commercially (Shanghai Bootech BioSci. and Technol., Shanghai, China). The proteins $(0.5 \mu \mathrm{g})$ were separated by sodium dodecyl sulfate polyacrylamide gel electrophoresis (SDS-PAGE) and transferred to a polyvinylidene fluoride (PVDF) membrane. The blots were incubated with the anti-EGFR sdAbs, followed by the incubation with protein A-HRP. The protein bands were detected by Beyo-enhanced chemiluminescence (BeyoECL) plus (Beyotime).

\section{Flow cytometric analysis (FACS)}

Cells were harvested and resuspended in ice-cold PBS containing BSA. Anti-EGFR sdAbs or negative control sdAbs were added and incubated with cells. An antiEGFR antibody (Santa Cruz Biotechnology, Dallas, TX, USA) was included as a positive control, and an isotype antibody (Santa Cruz Biotechnology) as a negative control. To detect the binding of the anti-EGFR sdAbs or negative control sdAbs, a protein A conjugated to 


\section{(See figure on next page.)}

Fig. 1 Selection of the five anti-EGFR sdAbs from a fully human sdAb phage library. a The P/N ratios of sdAbs derived from a fully human sdAb phage library increased along with each round of library screening. $\mathbf{b}$ The output phages derived from each round of library screening against the EGFR protein fragment were used for polyclonal phage ELISA. PBS was included as a control. Data are shown as mean \pm S.D. $(n=5) .{ }^{*} P<0.01$ vs. the respective PBS control. c The output phages derived from the fifth round of library screening were collected. After TG1 was infected with the phages, phage clones were randomly picked, and their binding to the EGFR protein fragment were tested by monoclonal phage ELISA. The results of representative 32 clones were shown. The arrow marked the phage clone which could specifically bind to EGFR. $\mathbf{d}$ The specific binding of EGFR to the phage clones were further examined by monoclonal phage ELISA with the EGFR protein fragment and the other eight unrelated proteins (VEGF, EndoF1, CampH, HER2, BMP2, SPB2, FGF21 and CXCR4) as negative controls. The results of representative 12 clones were shown. The arrows marked the phage clones which specifically bound to EGFR. e The peptide sequences of the five anti-EGFR sdAbs (aEG1B4, aEG2C7, aEG2E12, aEG4D9 and aEG6B2) were predicted from their nucleotide sequences by the DNAMAN software. Complementarity determining regions (CDR) and framework region (FR) were indicated

fluorescein isothiocyanate (FITC) (Abcam, Cambridge, MA, USA) was used. A mouse IgG kappa binding protein conjugated to phycoerythrin (PE) (Santa Cruz Biotechnology) was used for the detection of binding of antiEGFR antibody as a positive control and isotype antibody as a negative control. FACS Calibur (BD Biosciences) was used for the detection of fluorescence associated with the live cells, and data were analyzed by FlowJo software (BD Biosciences).

\section{MTT assay}

For MTT assay, $5 \times 10^{3}$ cells per well were seeded in 96-well plates and cultured in a $5 \% \mathrm{CO}_{2}$ humidified incubator for $24 \mathrm{~h}$ at $37{ }^{\circ} \mathrm{C}$. After cell medium was removed, cells were starved in serum-free medium for $4 \mathrm{~h}$. Different concentrations $(0,25,50$ and $100 \mu \mathrm{g} / \mathrm{ml})$ of the purified sdAbs were added, and the plates were incubated for $72 \mathrm{~h}$ at $37{ }^{\circ} \mathrm{C}$. Then, $100 \mu \mathrm{l} \mathrm{of} 1 \mathrm{mg} / \mathrm{ml}$ MTT (Sigma-Aldrich) was added, and the plates were incubated for $4 \mathrm{~h}$. MTT was moved, and $100 \mu \mathrm{l}$ of DMSO (Sigma-Aldrich) was added. The plates were incubated for $10 \mathrm{~min}$ at $37^{\circ} \mathrm{C}$ with shaking. Absorbance was measured at $570 \mathrm{~nm}$ by an automated microplate reader (Bio-RAD 680).

\section{Apoptosis assay}

Apoptosis assay was performed using an Annexin V/PI apoptosis detection kit (Sangon Biotech) according to the manufacturer's protocol. A total of $5 \times 10^{5}$ cells were cultured overnight in 6-well plates. Cells were starved by the incubation in serum-free medium for $4 \mathrm{~h}$, and the plates were washed twice with PBS. Cell medium containing $50 \mathrm{ng} / \mathrm{ml}$ of the purified sdAbs was then added. Cells were harvested after $48 \mathrm{~h}$ incubation, washed once with cold PBS and resuspended in $1 \times$ binding buffer at $2 \times 10^{6}$ cells $/ \mathrm{ml}$. Cells were incubated with $5 \mu \mathrm{l}$ of Annexin V-FITC and $10 \mu \mathrm{l}$ of propidium iodide (PI) for $10-15 \mathrm{~min}$ at room temperature and protected from light. Cells were examined by a flow cytometry (BD Biosciences), and data were analyzed by FlowJo software (BD Biosciences).

\section{Cell scratch assay}

The effect of the anti-EGFR sdAbs on the cell migration was evaluated by cell scratch assay. A total of $2 \times 10^{5}$ cells were cultured in 12-well plates at $37^{\circ} \mathrm{C}$. When cell confluence reached at $90 \%$, the cells were starved by the incubation for $4 \mathrm{~h}$ in serum-free medium. A single straight scratch was made across the center of the cell monolayer in each well by using a sterile $200 \mu$ pipette tip. Plates were washed, and different concentrations $(0$, $25,50,100 \mu \mathrm{g} / \mathrm{ml}$ ) of the purified anti-EGFR sdAbs or the negative control sdAbs in $500 \mu \mathrm{l}$ of medium containing 1\% FBS (Invitrogen) was added into each well. Images were photographed by an inverted optical microscope (Nikon, Tokyo, Japan) at $100 \times$ magnification after 0 and $24 \mathrm{~h}$ following making a scratch on the cell monolayer. Scratch widths were measured using the Image-Pro Plus 6.0 software (Media Cybernetics, Rockville, MD, USA). Cell migration rate (\%) was calculated by the formula: $\mathrm{Lm}=(\mathrm{L} 0-\mathrm{Lt}) / \mathrm{L} 0 \times 100 \%$, where $\mathrm{Lm}$ refers to the cell migration rate (\%), L0 refers to scratch width at $0 \mathrm{~h}$, and Lt refers to scratch width at $24 \mathrm{~h}$.

\section{Transwell assay for detecting the cell migration and invasion}

Transwell assay was used for the evaluation of effect of anti-EGFR sdAbs on cell migration. Transwells $(8 \mu \mathrm{m}$ pore size, BD Biosciences) were placed in 24-well plates. A total of $2 \times 10^{4}$ cells in $200 \mu \mathrm{l}$ of medium containing $1 \%$ FBS (Invitrogen) and different concentrations ( $0,25,50$, or $100 \mu \mathrm{g} / \mathrm{ml}$ ) of the purified sdAbs were added into the upper chamber of each transwell, and $600 \mu \mathrm{l}$ of medium containing $20 \%$ FBS was added to each well of the 24-well plates. After the incubation for $24 \mathrm{~h}$ at $37^{\circ} \mathrm{C}$, cells remaining on the upper chamber membrane were wiped off with a cotton-tipped applicator, and the upper chambers were washed twice with PBS. Cells which migrated across the chamber membrane were fixed for $30 \mathrm{~min}$ with $4 \%$ paraformaldehyde (Sigma-Aldrich). Then, cells were stained with $0.1 \%$ crystal violet (Beyotime) for $30 \mathrm{~min}$ at room temperature. An inverted optical microscope (Nikon) 
a

\begin{tabular}{|c|c|c|c|c|c|c|}
\hline Round & $\begin{array}{l}\text { Antigen } \\
(\mathbf{u g} / \mathrm{ml})\end{array}$ & $\begin{array}{l}\text { Input } \\
\text { phage } \\
\text { (pfu) }\end{array}$ & $\begin{array}{c}\text { Output } \\
\text { phage } \\
\text { (pfu) } \\
\text { (P) }\end{array}$ & $\begin{array}{c}\text { Output phage } \\
\text { of negative control } \\
\text { (pfu) } \\
\text { (N) }\end{array}$ & $\begin{array}{c}\text { Recovery } \\
\text { Rate } \\
\text { (P/input } \\
\text { phage) }\end{array}$ & $\mathbf{P} / \mathbf{N}$ \\
\hline 1 & 100 & $5 \times 10^{12}$ & $5.38 \times 10^{5}$ & $1.64 \times 10^{5}$ & $1.07 \times 10^{-7}$ & 3.28 \\
\hline 2 & 50 & $5 \times 10^{12}$ & $2.15 \times 10^{7}$ & $1.52 \times 10^{6}$ & $4.3 \times 10^{-6}$ & 14.1 \\
\hline 3 & 50 & $5 \times 10^{12}$ & $4.11 \times 10^{8}$ & $1.0 \times 10^{7}$ & $8.22 \times 10^{-5}$ & 41.1 \\
\hline 4 & 25 & $5 \times 10^{12}$ & $4.35 \times 10^{9}$ & $4.5 \times 10^{7}$ & $8.7 \times 10^{-4}$ & 96.8 \\
\hline 5 & 25 & $5 \times 10^{12}$ & $9.74 \times 10^{9}$ & $7.0 \times 10^{7}$ & $1.94 \times 10^{-3}$ & 139.1 \\
\hline
\end{tabular}

c
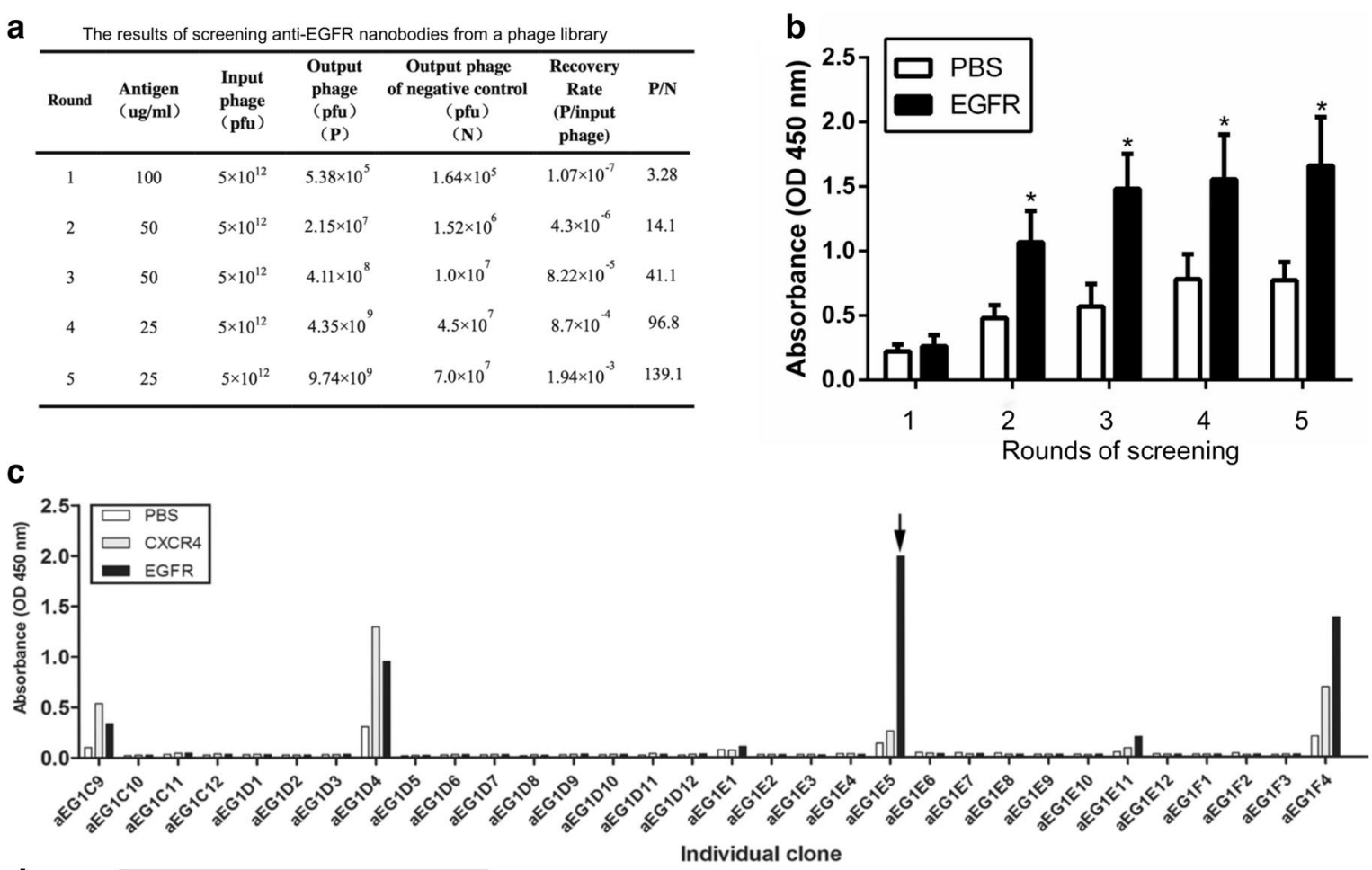

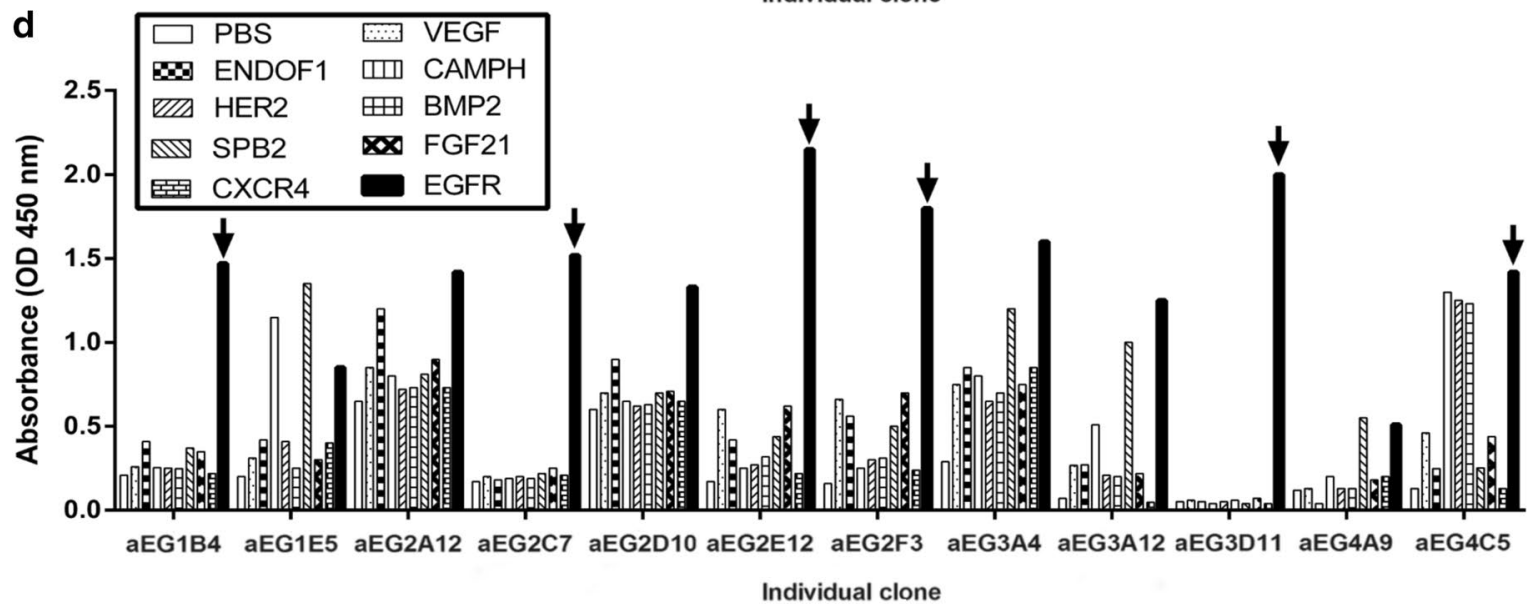

e

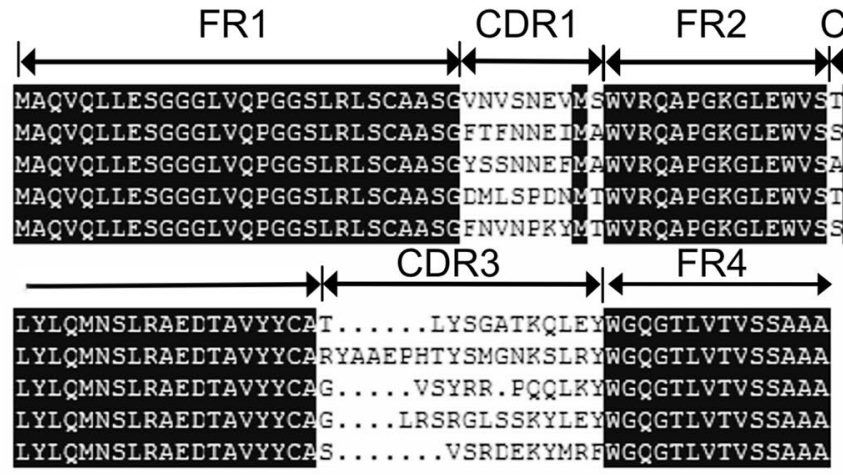




\section{(See figure on next page.)}

Fig. 2 Purification and characterization of the five anti-EGFR sdAbs. a SDS-PAGE was performed to examine the five anti-EGFR sdAbs (aEG1B4, aEG2C7, aEG2E12, aEG4D9 and aEG6B2). Left lane, protein marker; lane 1, uninduced total bacterial protein; lane 2, induced total bacterial protein; lane 3, insoluble fraction after bacterial breakage; lane 4, soluble fraction after bacterial breakage; lane 5, flow-through fraction; lane 6, wash buffer; lane 7-11, fractions collected from the protein purification column. The sdAb positions were marked by the arrows. $\mathbf{b}$ The specific binding of the five purified anti-EGFR sdAbs to the EGFR protein fragment was evaluated with ELISA. EGFR protein fragment and the other seven unrelated proteins (VEGF, EndoF1, CampH, HER2, BMP2, FGF21 and CXCR4) as negative controls were included. c Western blot analysis was performed with the five purified anti-EGFR sdAbs against the EGFR complete extracellular fragment purchased commercially (lane 2) and PBS as a control (lane 1). The specific binding of the five purified anti-EGFR sdAbs to cancer cells was examined by flow cytometric analysis ( $\mathbf{d}-\mathbf{h})$. The three human cancer cell lines A549 (d), MCF-7 (e) and DU145 (f) were tested. The two cell lines 293T (g) and 3T3 (h) were included as negative controls. Black curves showed the background staining with an isotype control primary antibody or no primary antibody. Red curves showed the staining with anti-EGFR antibody purchased commercially as a positive control, the five purified anti-EGFR sdAbs (aEG1B4, aEG2C7, aEG2E12, aEG4D9 and aEG6B2), or the two purified sdAbs (aVE201 and aHer2-13C1) as negative controls

was used for photographing images at $100 \times$ magnification. Cells stained with crystal violet were dissolved in $33 \%$ acetic acid solution, and absorbance at $570 \mathrm{~nm}$ was measured by an automated microplate reader (Bio-RAD 680).

Transwell assay was also performed to detect the cell invasion as described above except each upper chamber of transwells was coated with $60 \mu \mathrm{l}$ of diluted matrigel (BD Biosciences) overnight at $37{ }^{\circ} \mathrm{C}$ before cells were added into transwells.

\section{Animal studies}

All animal experiments were performed in accordance with the protocols approved by the Institutional Animal Care and Use Committee of Jinan University. Male BALB/c nude mice (4 weeks old) were purchased from Guangdong Medical Experimental Animal Center (Guangzhou, China). Mice were housed in air-filtered laminar flow cabinets with a $12 \mathrm{~h}$ light cycle. A total of $5 \times 10^{6}$ A549 cells in $0.1 \mathrm{ml}$ of serum-free medium were injected subcutaneously in the right flank. When tumor sizes reached approximately $100 \mathrm{~mm}^{3}$ on average, mice were randomly divided into six groups (five mice/group). The test reagents ( $10 \mathrm{mg}$ sdAbs $/ \mathrm{kg}$ or $2 \mathrm{mg}$ $\mathrm{DDP} / \mathrm{kg}$ ) were injected intravenously once every 3 days. Tumor volumes $\left(\mathrm{mm}^{3}\right)$ were calculated by the formula: $0.5 \times\left(\right.$ length $\times$ width $\left.^{2}\right)$.

\section{Immunohistochemistry}

Mice were sacrificed on the 24th day following the first injection of the test reagents, and tumors were removed. Tumors were fixed with formalin and embedded in paraffin. The $4 \mu \mathrm{m}$ paraffin sections were stained by hematoxylin-eosin (HE, Beyotime).

For immunohistochemistry, $4 \mu \mathrm{m}$ paraffin sections were incubated with each of primary antibodies (antiKi67, anti-CD31 and anti-caspase 3, Sigma-Aldrich) at 1:200 dilution overnight at $4{ }^{\circ} \mathrm{C}$. The sections were washed three times with PBS for $5 \mathrm{~min}$ each and incubated with HRP-labeled goat anti-rat secondary antibody (Sigma-Aldrich). After the incubation for $1 \mathrm{~h}$ at $37{ }^{\circ} \mathrm{C}$, the sections were washed three times with PBST for $5 \mathrm{~min}$ each and incubated with diaminobenzidine (DAB) chromogen (Sigma-Aldrich) for 3-5 min to show a dark brown color. The sections were photographed using an Olympus IX70 light microscope (Olympus, Tokyo, Japan), and the integrated optical density (IOD) of each image was analyzed with Image-Pro Plus analysis software (Media Cybernetics).

\section{Statistical analysis}

Data were expressed as mean \pm standard deviation (SD). All graphs were prepared with Graphpad Prism version 8.0 (Graphpad, La Jolla, CA, USA). Statistical analysis was performed using a one-way analysis of variance test (one-way ANOVA). For all statistical comparisons, $P<0.05$ was considered statistically significant, whereas $P<0.01$ was considered very significant.

\section{Results}

\section{Screening a fully human sdAb phage library for anti-EGFR} sdAbs

The phage display sdAb library was rescued by the M13 helper phage. Five rounds of library screening against EGFR fragment were carried out. The results of library screening were shown in Fig. 1a, and the enrichment ratio $(\mathrm{P} / \mathrm{N})$ increased to 139.1 after five round rounds of screening. Screened phages were tested for their binding to the EGFR fragment by the polyclonal phage ELISA. The results showed that sdAbs targeting EGFR were significantly enriched in the screening (Fig. 1b).

Subsequently, 448 phage clones were randomly picked from the fifth round of screening and tested for their binding to EGFR fragment by monoclonal phage ELISA. The results of the representative 32 clones were shown in Fig. 1c. The 24 clones showed strong binding to EGFR and were further tested by monoclonal phage ELISA by including the EGFR fragment and the 
a
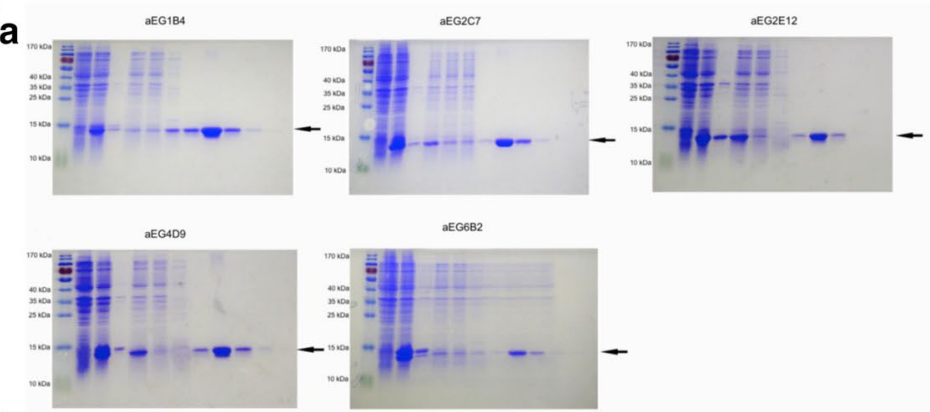

b

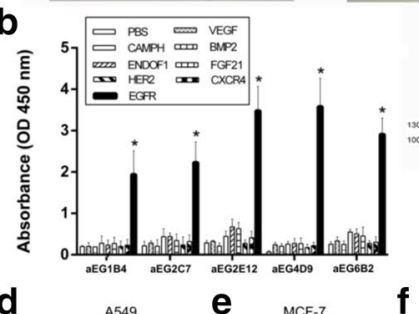

C
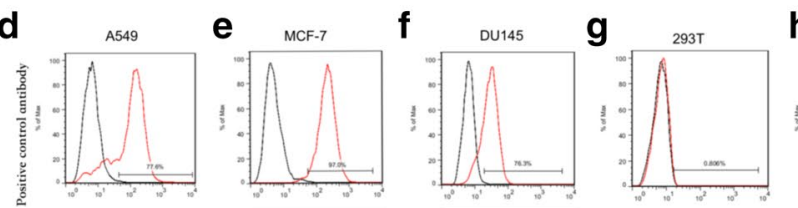

h
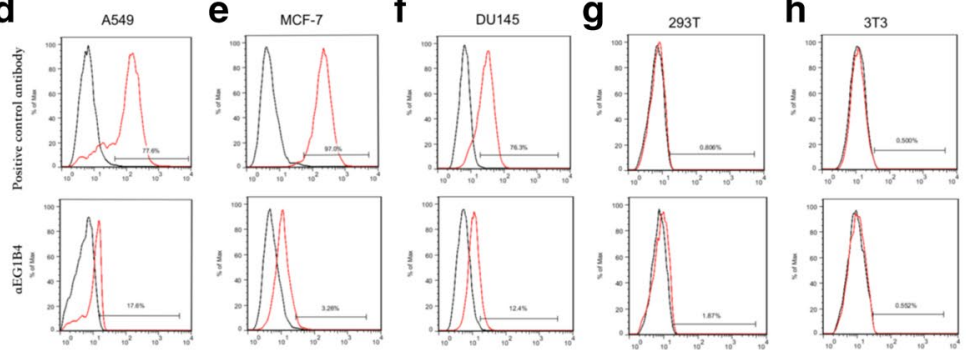

称:
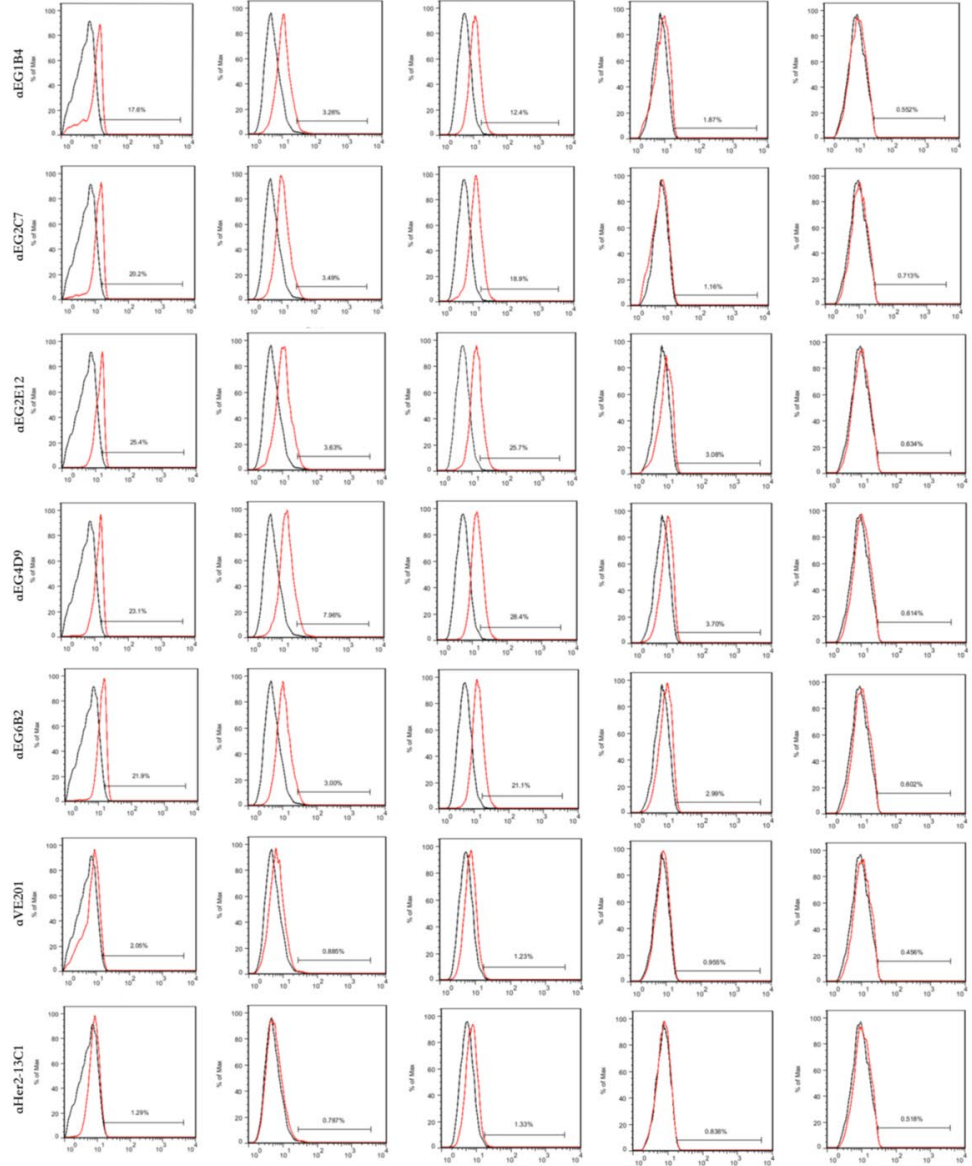
(See figure on next page.)

Fig. 3 Effect of the five anti-EGFR sdAbs on inhibiting cell proliferation and promoting cell apoptosis. The inhibition of cell proliferation by the five anti-EGFR sdAbs (aEG1B4, aEG2C7, aEG2E12, aEG4D9 and aEG6B2) was tested by MTT assay on cancer cells A549 (a), MCF-7 (b) and DU145 (c). Cells were treated with different concentrations $(0,25,50$ and $100 \mu \mathrm{g} / \mathrm{ml}$ ) of the anti-EGFR sdAbs. Two sdAbs (aVE201 and aHer2-13C1) were included as negative controls. Effect of the five anti-EGFR sdAbs on apoptosis was evaluated by apoptosis assay with cancer cells A549 (d, e), MCF-7 (f, $\mathbf{g})$ and DU145 (h, i). Cells were incubated with $50 \mathrm{\mu g} / \mathrm{ml}$ of the anti-EGFR sdAbs. Annexin V-FITC was used to determine the percentage of cells undergoing apoptosis at an early stage, and propidium iodide (PI) was used to distinguish between viable and nonviable cells. Two sdAbs (aVE201 and aHer2-13C1) were included as negative controls. Data are shown as mean \pm S.D. $(n=5)$. For $\mathbf{a}-\mathbf{c},{ }^{*} P<0.05$ and ${ }^{* *} P<0.01$ vs. the respective control $(0 \mu \mathrm{g} / \mathrm{ml})$; for $\mathbf{e}, \mathbf{g}$ and $\mathbf{i},{ }^{*} P<0.05$ and ${ }^{* *} P<0.01$ vs. PBS control

other eight unrelated proteins (VEGF, EndoF1, CampH, HER2, BMP2, SPB2, FGF21 and CXCR4) as negative controls. The results showed that 13 phage clones could specially bind to EGFR fragment and not to the other eight unrelated proteins (Fig. 1d). These 13 phage clones were DNA-sequenced, and the five different sdAbs were obtained, including aEG1B4 (accession number: LR743560), aEG2C7 (accession number: LR743561), aEG2E12 (accession number: LR743562), aEG4D9 (accession number: LR743563) and aEG6B2 (accession number: LR743564) (Fig. 1e). These five sdAbs share the same four framework regions (FR1-4) and have different CDR1-3.

\section{Expression and characterization of the five anti-EGFR sdAbs}

For expression of these five sdAbs, the coding sequences of the sdAbs were sub-cloned into the $\mathrm{pET}-22 \mathrm{~b}$ vector under the T7 promoter, and the plasmids were transformed into E. coli BL21 (DE3). The expression of soluble sdAb proteins was induced by IPTG, and the proteins were purified by a $\mathrm{Ni}^{+}-\mathrm{NTA}$ resin column. The eluted proteins were separated on SDS-PAGE gel and visualized by coomassie brilliant blue staining, and each purified sdAb showed a single band marked by an arrow (Fig. 2a).

The sdAbs were tested by ELISA for their binding to EGFR fragment and the seven unrelated proteins (VEGF, EndoF1, CampH, HER2, BMP2, FGF21 and CXCR4) as negative controls. The results showed that all of these five sdAbs specifically bound to EGFR fragment and not the seven unrelated proteins, and two (aEG2E12 and aEG4D9) of them showed the higher binding than the others (Fig. 2b). These sdAbs were further tested by Western blotting for their binding to EGFR complete extracellular fragment purchased commercially, and the results showed that all of the five sdAbs could bind to EGFR complete extracellular fragment, and two (aEG2E12 and aEG4D9) of them showed higher signal than the others (Fig. 2c) and were chosen for further testing by animal studies.

In addition, the sdAbs were tested by flow cytometric analysis for their binding to cancer cells. The results showed that the five anti-EGFR sdAbs specifically bound to the human cancer cells A549, MCF-7 and DU145 and not the cells 293T and 3T3 as negative controls (Fig. 2dh). The anti-EGFR antibody purchased commercially was included as a positive control and showed the results similar to the five anti-EGFR sdAbs. Two sdAbs (aVE201 and aHer2-13C1) were included as negative controls. These two sdAbs (aVE201 and aHer2-13C1) were isolated previously in our laboratory in a different study from the same human DAb library (previously unpublished data) and could not bind to EGFR. Their proteins were purified with the same method as the five anti-EGFR sdAbs.

\section{The anti-EGFR sdAbs inhibited cancer cell proliferation and increased their apoptosis}

The sdAbs were tested by MTT assay for their effect on the proliferation of cancer cells A549, MCF-7 and DU145. The results showed that the cell proliferation was significantly inhibited by all the five sdAbs in a dosedependent manner (Fig. 3a-c). More inhibition was seen at the higher sdAb concentrations. Two sdAbs (aVE201 and aHer2-13C1) were included as negative controls and showed no inhibition on cell proliferation at all the concentrations.

Effect of the sdAbs on cancer cell apoptosis was also investigated by apoptosis assay. The results showed that all the five anti-EGFR sdAbs significantly increased cancer cell apoptosis at the concentration of $50 \mu \mathrm{g} / \mathrm{ml}$ (Fig. 3d-i). The two sdAbs (aVE201 and aHer2-13C1) were included as negative controls and did not increase cell apoptosis of all the three cancer cell lines.

\section{Anti-EGFR sdAbs inhibited cancer cell migration and invasion}

Effect of the sdAbs on cancer cells migration was investigated by the cell scratch assay. The results showed that all the five sdAbs could inhibit the migration of all the three cancer cell lines (Fig. 4). The inhibition was generally concentration-dependent. The two sdAbs (aVE201 and aHer2-13C1) were included as negative controls and showed no inhibition on cell migration.

Effect of the five sdAbs on cancer cell migration and invasion was also examined by the transwell assay. Data 

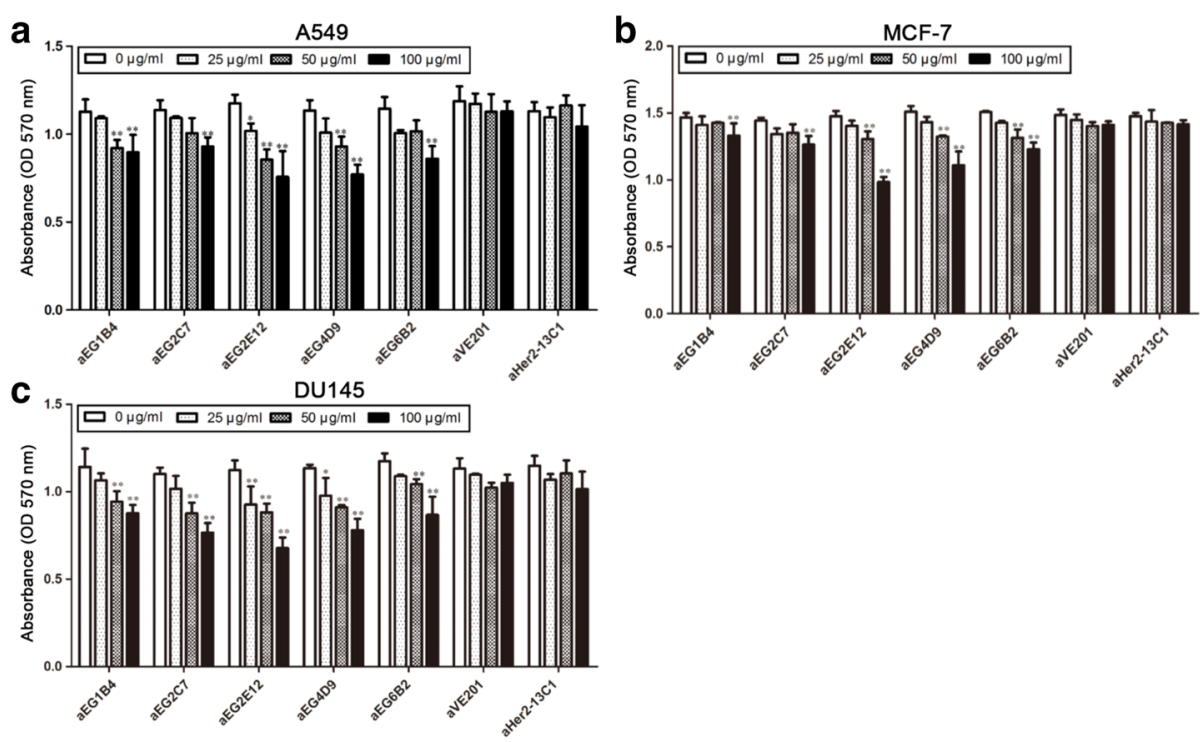

d
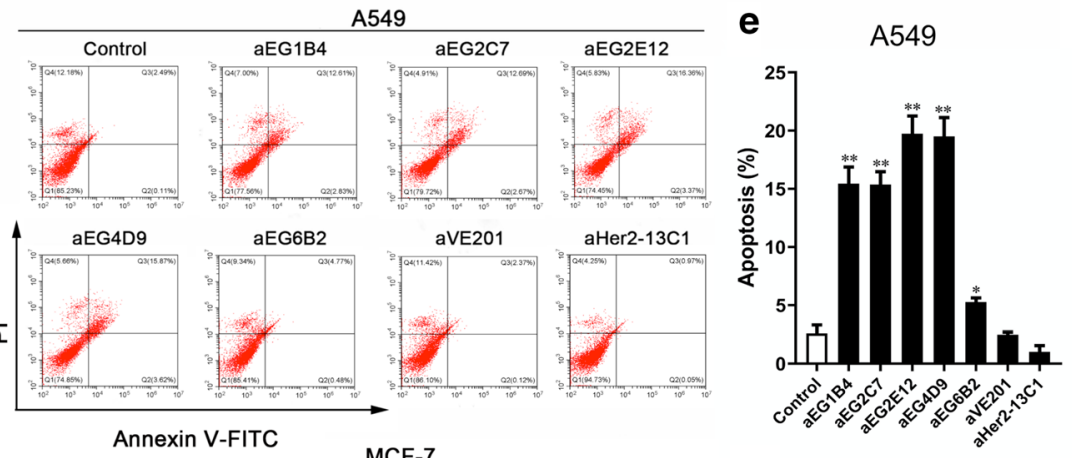

f
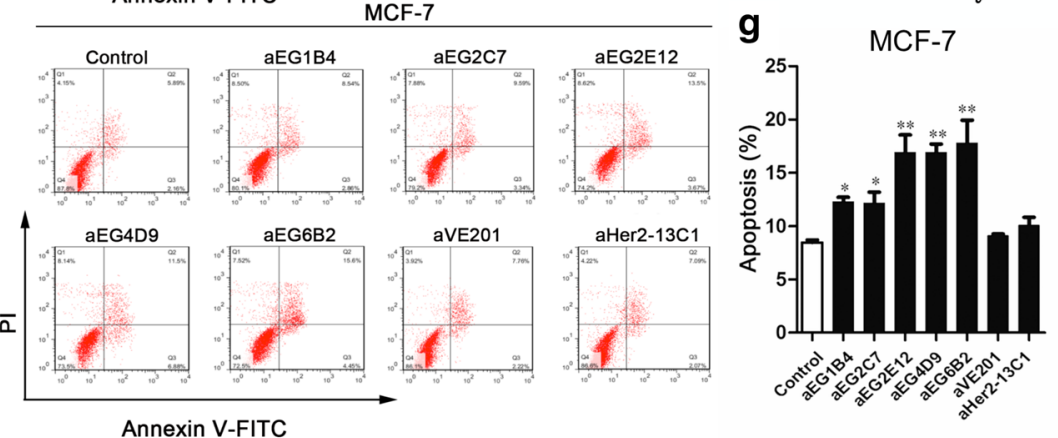

h
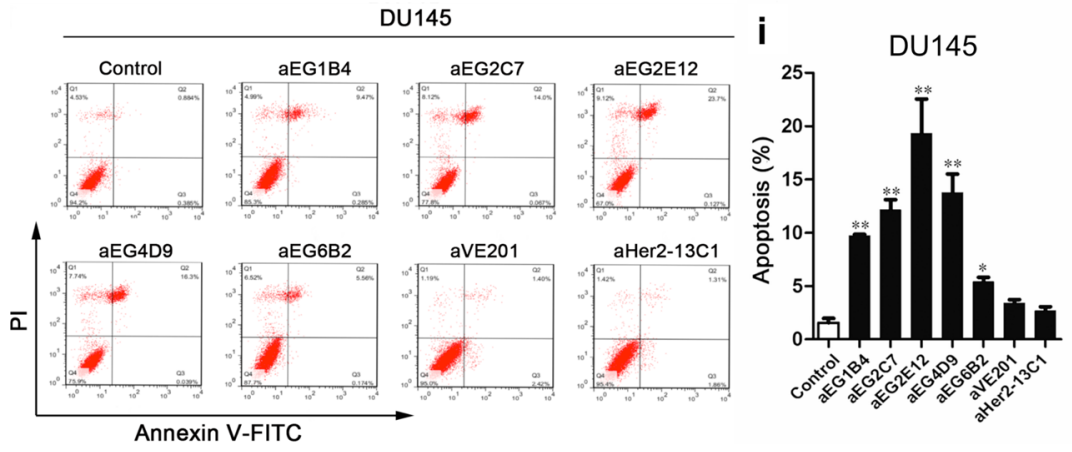


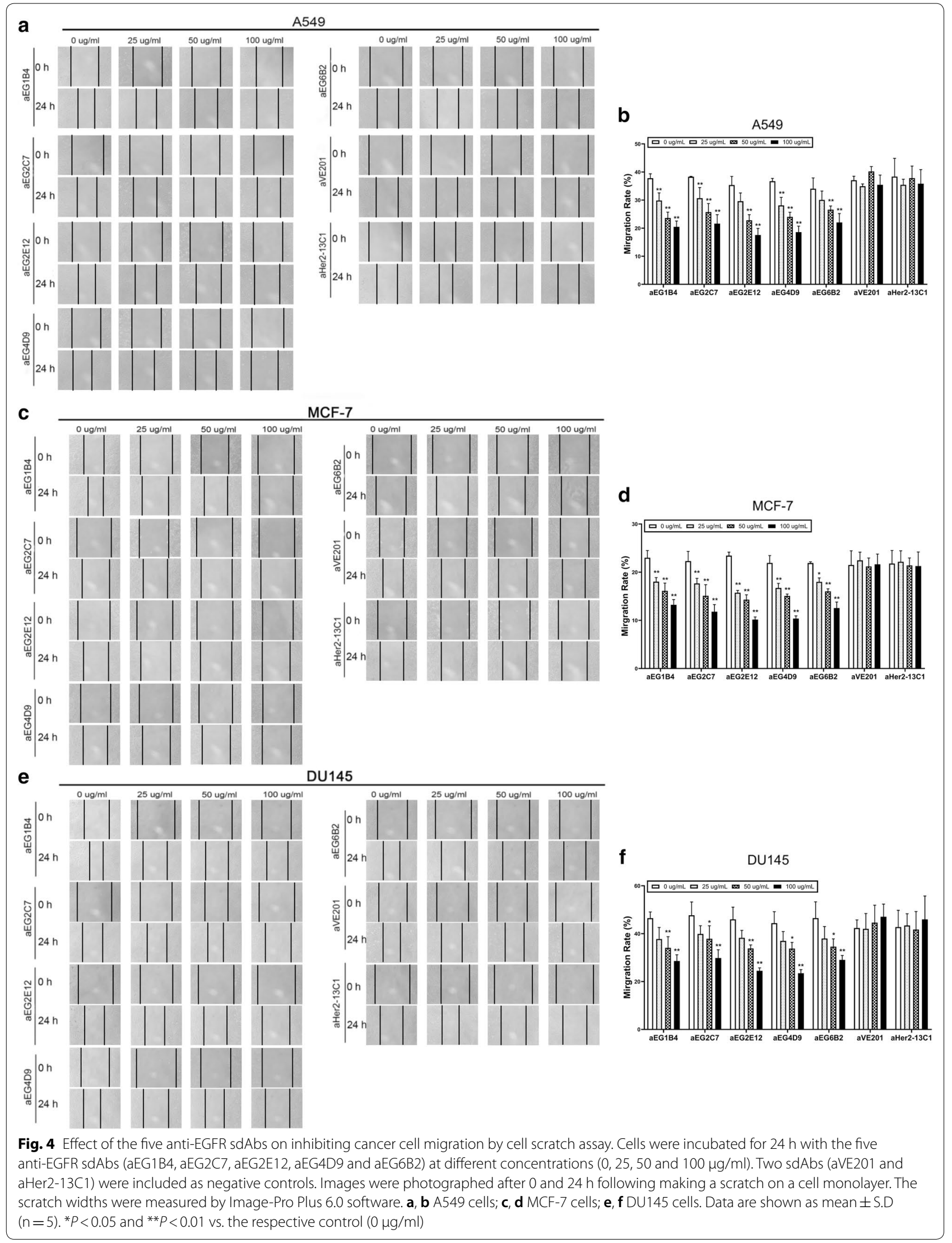


showed that all the five anti-EGFR sdAbs could inhibit the migration (Fig. 5a-f) and invasion (Fig. $5 \mathrm{~g}-\mathrm{l}$ ) of all the three cancer cell lines in a dose-dependent manner.

\section{Two sdAbs inhibited tumor growth in vivo}

Cancer cell A549 mouse xenograft model was used to validate the anti-tumor potential of the sdAbs in vivo. The two sdAbs aEG2E12 and aEG4D9 were selected for this study and the two sdAbs (aVE201 and aHer2-13C1) were included as negative controls. When the tumors reached an average volume of $100 \mathrm{~mm}^{3}$, BALB/c nude mice were injected intravenously with PBS, $2 \mathrm{mg} / \mathrm{kg}$ of DDP as positive control, $10 \mathrm{mg} / \mathrm{kg}$ of anti-EGFR sdAbs (aEG2E12 and aEG4D9) and negative control sdAbs (aVE201 and aHer2-13C1) every 3 days. The results showed that the two anti-EGFR sdAbs significantly inhibited the tumor growth compared with the PBS and the two sdAbs as negative controls (Fig. 6a-c). The inhibition of tumor growth by the two anti-EGFR sdAbs was comparable with DDP.

\section{Two sdAbs inhibited cancer cell proliferation and increased} their apoptosis in vivo

To preliminarily study the mechanisms how the antiEGFR sdAbs inhibited cancer cell growth in vivo, immunohistochemistry was performed with the tumors taken from the mouse tumor xenograft model. Tumor cell proliferation was detected by anti-Ki67 antibody, tumor angiogenesis by anti-CD31 antibody, and tumor cell apoptosis by anti-caspase 3 antibody. The results demonstrated that the two anti-EGFR sdAbs and DDP inhibited tumor cell proliferation, increased tumor cell apoptosis and did not show effect on tumor angiogenesis (Fig. 6d, e). On the other hand, PBS and the two sdAbs as negative controls had no effect on tumor cell proliferation, angiogenesis and apoptosis.

\section{Discussion}

Chemotherapy and radiotherapy are commonly used for cancer therapy, but they usually result in low cure rate and cause serious side effects. New cancer therapies with reduced toxicity and elevated efficacy have been pursued. Although mAbs have been successful for cancer therapy, they have many disadvantages including low efficacy, high side-effect and high cost, and these limit their applications. The mAb major disadvantages are described as follows.

First, mAbs are very large in size and are difficult to penetrate into tumor tissues, so that the mAb efficacy is limited. In solid tumors, the cancer cells are in the increased state of hypoxia and interstitial fluid pressure due to the broken-down of homeostatic regulation [24]. The tumor extracellular matrix (ECM) hinders the movement of mAb into the tumor tissues [25]. Thus, some attempts have been made to develop smaller antibodies, which still preserve the specificity and affinity of the conventional mAbs and have lower immunogenicity to decrease the immune rejection. In this study, the five anti-EGFR sdAbs of only $15 \mathrm{kDa}$ were identified and could specifically bind to EGFR and the human cancer cells. They could significantly inhibit cancer cell proliferation in vitro and tumor growth in vivo.

Second, mAbs for cancer therapy are normally isolated from mouse and are mouse antibodies against human proteins. Mouse antibody is recognized as a foreign antigen in human and can be rejected by human immune system, which can result in rapid mouse antibody clearance, low anti-tumor efficacy or hypersensitivity reactions in human body [12]. As the development of genetic engineering, humanized antibody or chimeric antibody were developed to reduce the antigenicity of mouse antibody [13]. Even though immunogenicity of the mouse antibody may be reduced, it cannot be completely eliminated. Moreover, the potential antibody immunogenicity may be increased by $\mathrm{mAb}$ formulation, aggregation and glycosylation and a cell line used to express the antibody. For instance, cetuximab produced in NSO cells contained alpha-galactose carbohydrate that caused hypersensitivity reaction in some allergic individuals [26].

Third, because human sdAb is small, it can access a hidden epitope that is not accessible to the large-size conventional $\mathrm{mAb}[20,21]$.

Fourth, mAbs need to be expressed in mammalian cells (usually $\mathrm{CHO}$ cells), and the manufacturing process is very expensive and leads to the high cost of $\mathrm{mAb}$ medicines. On the other hand, human sdAb of about $15 \mathrm{kDa}$ consists of only the variable domain of the human antibody heavy chain $(\mathrm{VH})$ and can be expressed in bacteria. The cost of sdAb production is much lower than $\mathrm{mAb}$ [27]. In this study, the five anti-EGFR sdAbs were expressed in E. coli BL21 and purified by $\mathrm{Ni}^{+}$-NTA chromatography. They could bind to EGFR and showed good anti-tumor activity in vitro and in vivo. Therefore, human $\mathrm{sdAb}$ is an ideal alternative for the conventional mAbs for cancer therapy.

Some cancer-specific proteins were identified. EGFR overexpression in certain cancer cells promoted tumor development and metastasis, and EGFR is the marker for poor cancer prognosis [28-30]. It also promoted tumor angiogenesis via inducing the expression of vascular 
(See figure on next page.)

Fig. 5 Effect of the five anti-EGFR sdAbs on inhibiting cell migration and invasion by the transwell assay. $\mathbf{a}-\mathbf{f}$ The inhibition of cancer cell migration by anti-EGFR sdAbs was shown. Cells in the medium containing 1\% FBS and the five purified anti-EGFR sdAbs (aEG1B4, aEG2C7, aEG2E12, aEG4D9 and aEG6B2) at different concentrations $(0,25,50$ or $100 \mu \mathrm{g} / \mathrm{ml}$ ) were seeded into the upper chambers of transwells. Two sdAbs (aVE201 and aHer2-13C1) were included as negative controls. After $24 \mathrm{~h}$ of incubation, cells which migrated to the bottom chamber membrane were stained with $0.1 \%$ crystal violet. Images were photographed. Crystal violet on the bottom chamber membrane was dissolved in $33 \%$ acetic acid solution, and absorbance at $570 \mathrm{~nm}$ was measured. a, b A549 cells; c, d MCF-7 cells; e, f DU145 cells. Detecting cell invasion (g-I) was performed as described above except each upper chamber of transwells was coated with $60 \mu$ of diluted matrix gel overnight at $37^{\circ} \mathrm{C}$ before cells and sdAbs were added into transwells. $\mathbf{g}$, h A549 cells; $\mathbf{i}, \mathbf{j}$ MCF-7 cells; $\mathbf{k}$, I DU145 cells. Data are shown as mean \pm S.D. $(n=5)$. ${ }^{*} P<0.05$ and ${ }^{* *} P<0.01$ vs. the respective control $(0 \mu \mathrm{g} / \mathrm{ml})$

endothelial growth factors (VEGF). Clinical application showed that the anti-EGFR antibodies were effective for cancer therapy, and EGFR was an important anticancer target [31]. Anti-EGFR mAbs and small molecule tyrosine kinase inhibitors (TKIs) targeting EGFR were approved by FDA for cancer therapy. Anti-EGFR mAbs including panitumumab, cetuximab and nimotuzumab were approved for treatment of NSCLC and colorectal cancer $[15,16,32]$.

The EGFR extracellular domain III is critical for EGF binding. Structural analysis of the EGFR-GC1118 (an anti-EGFR mAb) crystal complex revealed that GC1118 recognizes linear and discrete $\mathrm{N}$-terminal epitopes of domain III of EGFR [33]. GC1118 exhibited potent inhibitory activity against high-affinity EGFR ligands in terms of EGFR binding, triggering EGFR signaling and proliferation [33]. The binding epitopes of two anti-EGFR mAbs approved by FDA (cetuximab and panitumumab) overlap with the EGF-binding site on the EGFR domain III [33]. Studies showed that these two antibodies could inhibit EGFR downstream pathway signalling, thus blocking the proliferation, migration and invasion of tumor cells by competing binding to EGFR with EGF [34]. Therefore, in this study, we chose an EGFR protein fragment located in the EGFR extracellular domain III for screening antiEGFR sdAbs from a sdAb phage library.

Previous studies showed that EGFR could induce intracellular tyrosine phosphorylation. Studies also indicated that EGF/EGFR signaling pathway was interacted with EGFR/ERK, EGFR/STAT3 and EGFR/mTOR signaling pathways $[3,4]$. These pathways are associated with promoting tumor cell proliferation, vitality, migration and invasion, tumorigenesis, tumor progression and metastasis and tumor angiogenesis in the tumor microenvironment $[5,6]$. In this study, the five anti-EGFR sdAbs inhibited cancer cell proliferation in vitro and tumor growth in vivo. Binding of the anti-EGFR sdAbs to the EGFR extracellular domain may prevent EGF from binding to EGFR, or homophilic cancer cell-cell adhesion through cell surface EGFR interaction. Further study is required to examine the mechanisms how these antiEGFR sdAbs inhibit cancer cell growth.

SdAb can be modified to increase its efficacy. For example, bi-specific sdAb can be generated by fusing two different sdAbs targeting EGFR antigen and a second antigen, respectively. The second antigen can include CD3, which is a T cell co-receptor and can activate $T$ cells or $C D 44$, which is a multifunctional cell surface molecule involved in cell proliferation, differentiation and migration and angiogenesis $[35,36]$. The anti-EGFR sdAbs can be fused to a toxic molecule to form an antibody-drug conjugate (ADC) to strengthen cancer cell killing [37]. A toxic molecule can include doxorubicin (DOX) and urease enzyme [38]. The antiEGFR sdAb can also be fused to a tumor penetrating peptide to enhance its penetration into tumor tissue and increase its efficacy for cancer therapy [39].

\section{Conclusions}

An EGFR protein fragment located at its extracellular domain III was chosen for screening a fully human sdAb library by phage display. Five anti-EGFR sdAbs were obtained, and they specifically bound to both an EGFR protein fragment and the EGFR complete extracellular domain purchased commercially. They also bound to the human cancer cells A549, DU145 and MCF-7. They could inhibit cancer cell proliferation, migration and invasion and induce cancer cell apoptosis. Furthermore, two anti-EGFR sdAbs (aEG2E12 and aEG4D9) were tested for their anti-tumor effect in vivo, and inhibited tumor growth in a lung cancer mouse model. This study demonstrates that these anti-EGFR sdAbs may become good alternative of mAbs for cancer therapy. 

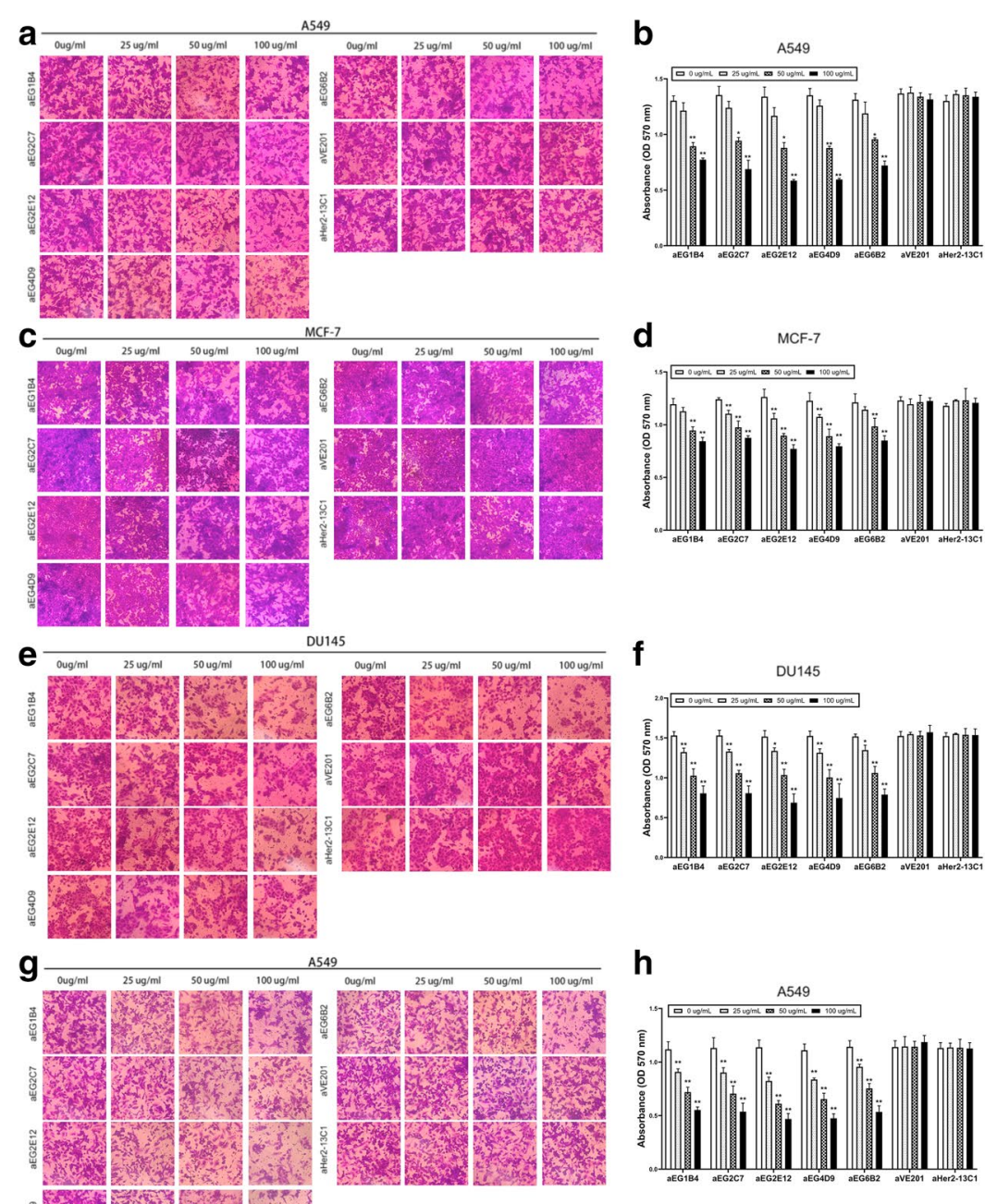

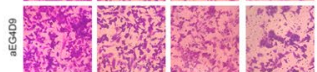

i
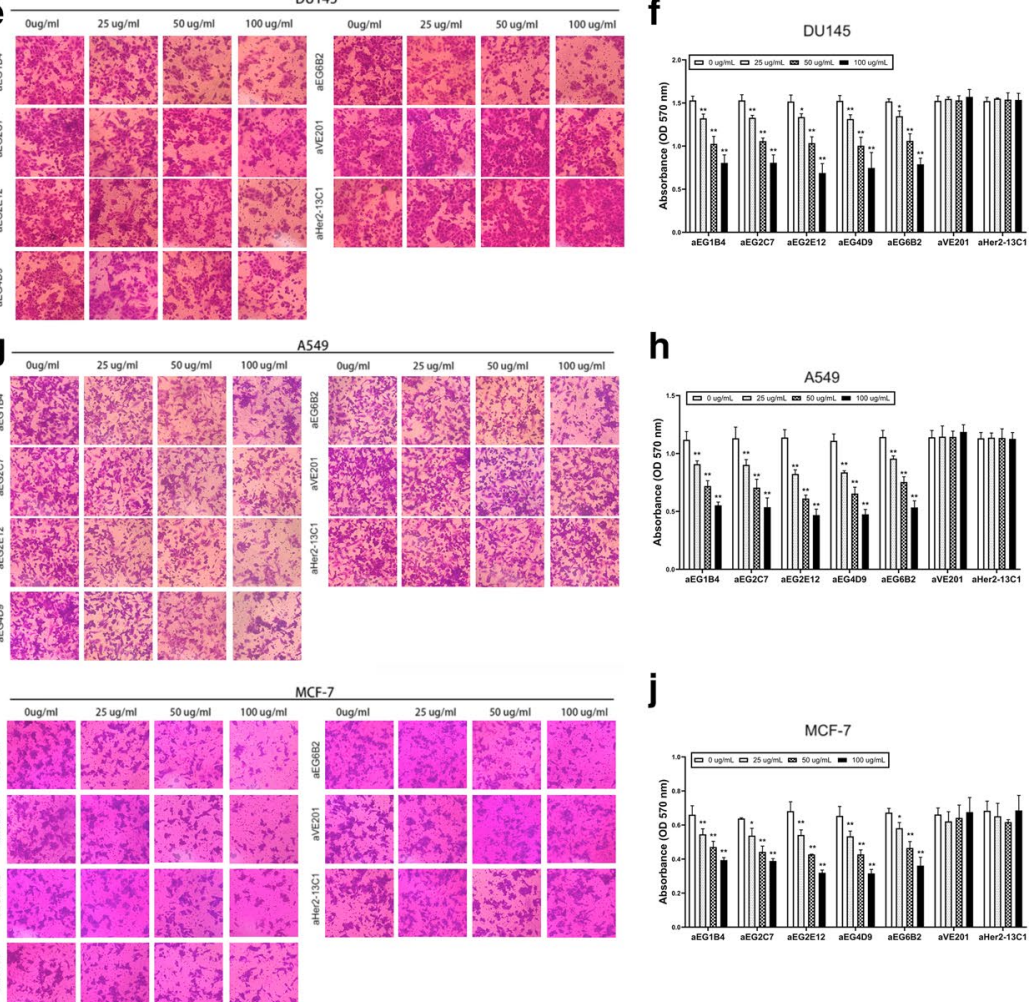

$\mathbf{h}$
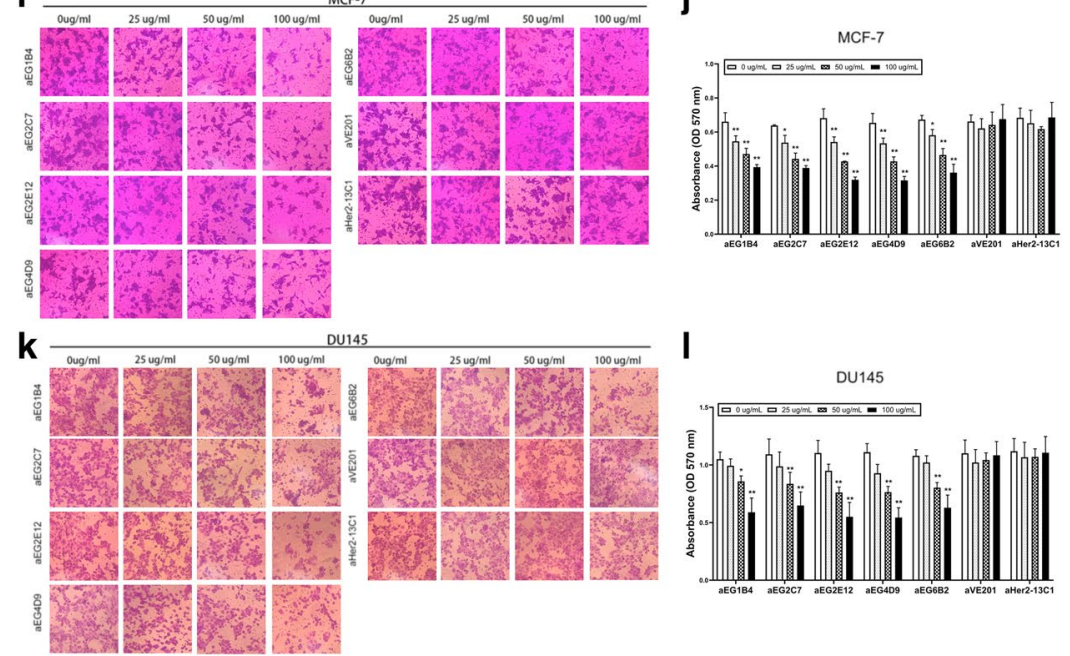


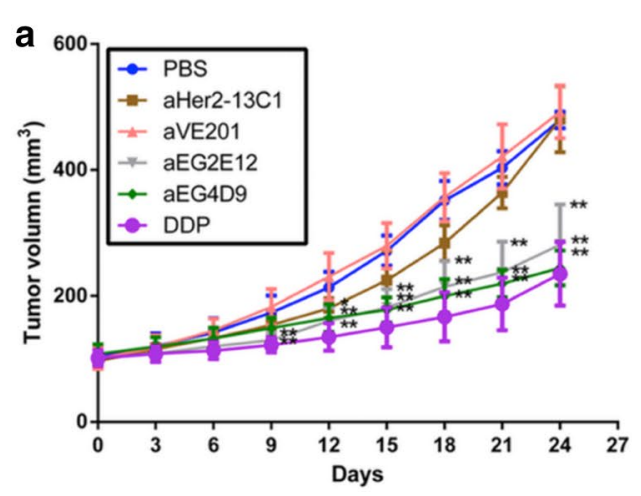

b
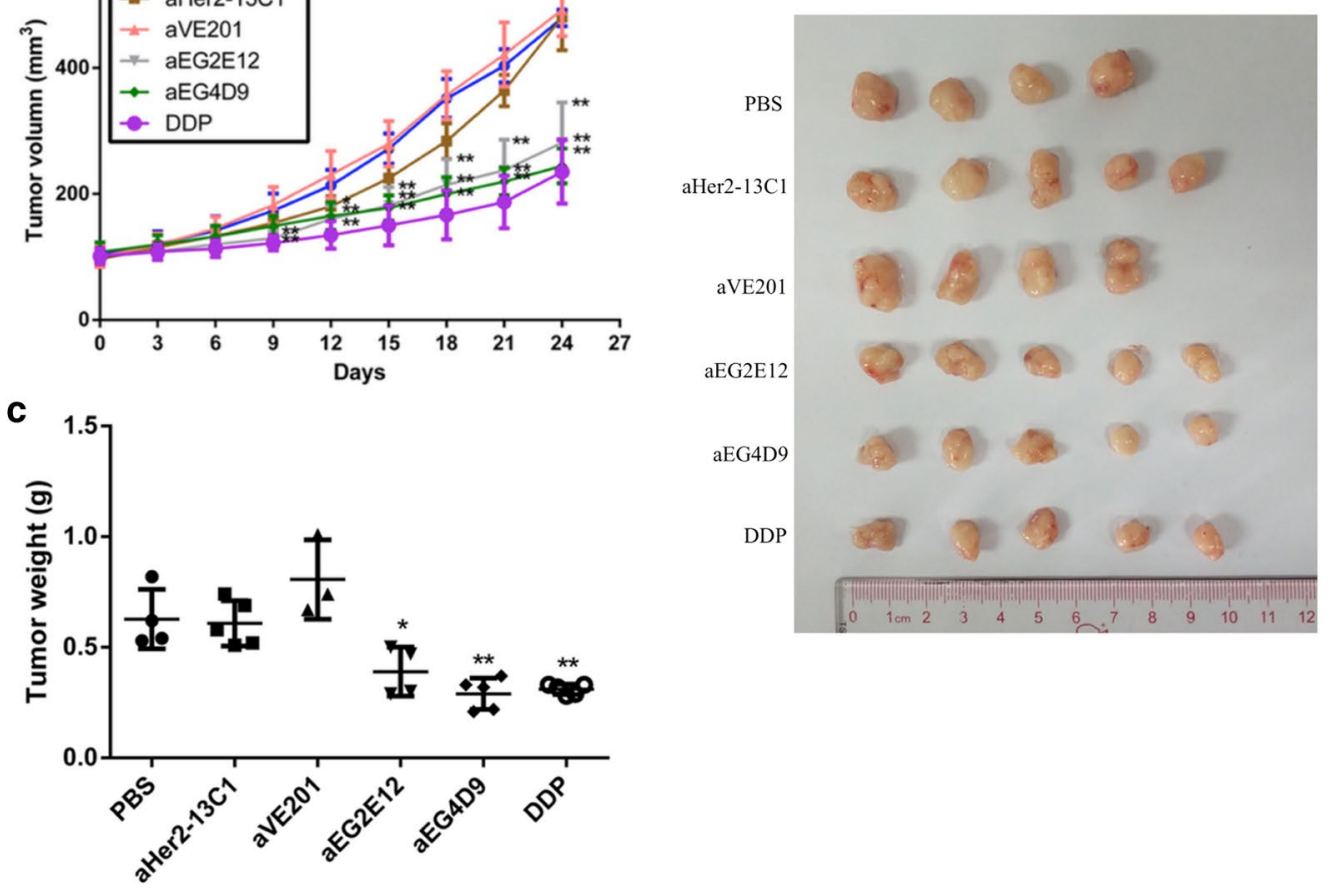

d

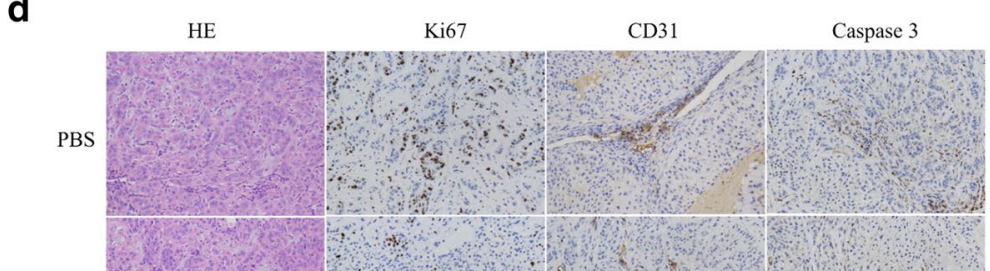

aHer2-13Cl
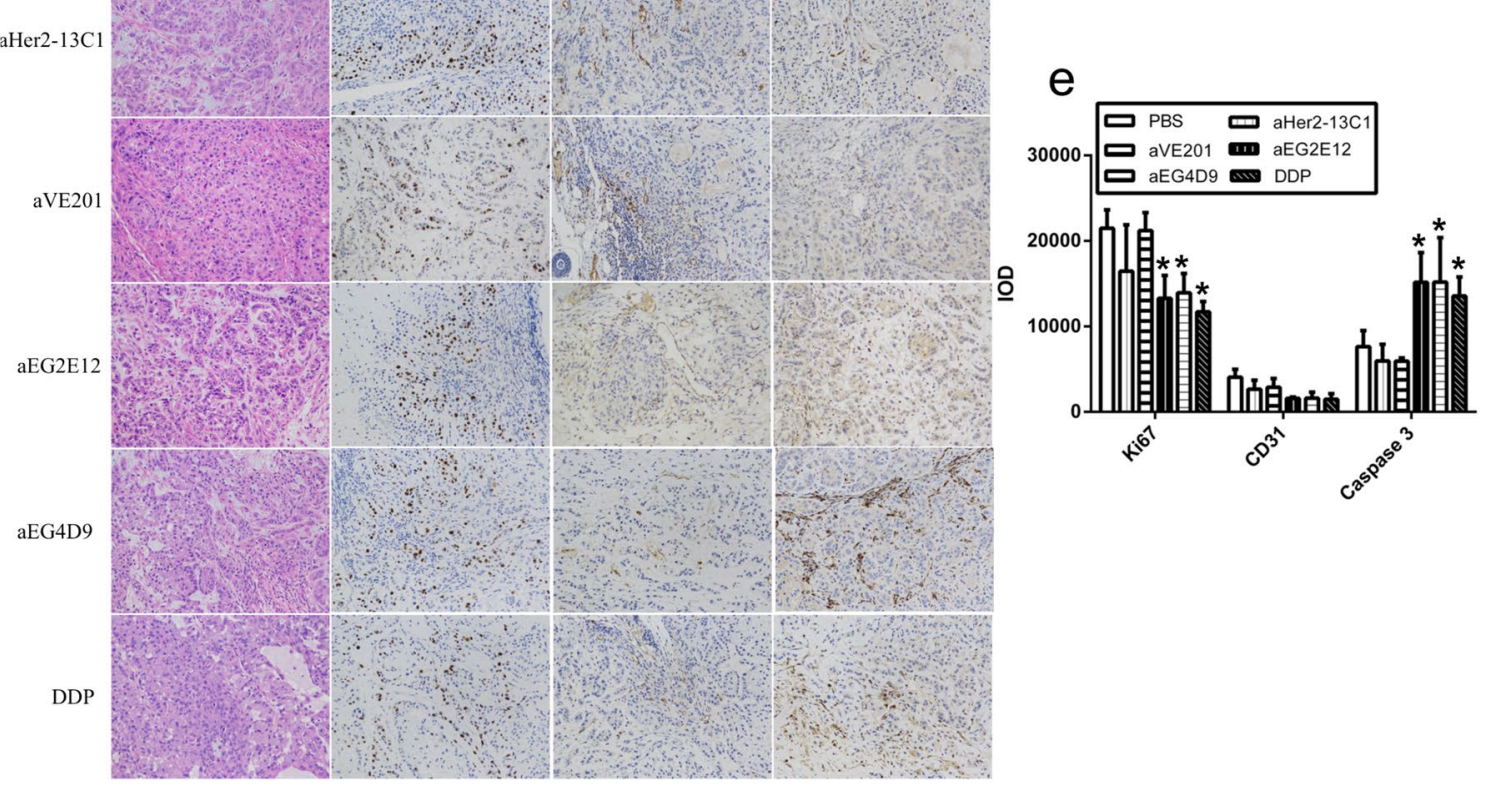


\section{(See figure on previous page.)}

Fig. 6 Inhibition of A549 xenograft growth in BALB/C nude mice by anti-EGFR sdAbs. A total of $5 \times 10^{6}$ A549 cells were injected into the right flank of each mouse. SdAbs were injected after tumor sizes reached to about $100 \mathrm{~mm}^{3}$. a Mice were injected with $10 \mathrm{mg} / \mathrm{kg}$ anti-EGFR sdAbs (aEG2E12 and aEG4D9) every 3 days. PBS, DDP (2 mg/kg) and two sdAbs (aVE201 and aHer2-13C1, $10 \mathrm{mg} / \mathrm{kg}$ ) were included as controls. b, c Mice were sacrificed on the 24th day following the first injections of the test reagents, and tumors were removed, photographed and weighted. $\mathbf{d}$ Tumor sections were stained by HE or examined with anti-Ki67, anti-CD31 and anti-caspase 3 antibodies. e Integral optical density (IOD) was calculated from $\mathbf{d}$ by Image-Pro Plus analysis software. Data are shown as mean \pm S.D. $(n=4)$. ${ }^{*} P<0.05$ and ${ }^{*} P<0.01$ vs. the respective PBS control

\section{Abbreviations}

SdAb: Single-domain antibody; DDP: Cis-platinum; EGFR: Epidermal growth factor receptor; ECD: Extracellular domain; ICD: Intracellular domain; EGFRECD: EGFR-extracellular domain; EGFR-ICD: EGFR-intracellular domain; mAbs: Monoclonal antibodies; scFv: Single-chain variable fragment; VH: Variable domains of the $\mathrm{mAb}$ heavy chain; $\mathrm{VL}$ : Variable domains of the $\mathrm{mAb}$ light chain; sdAb: Single-domain antibody; Protein A-HRP: Protein A-horseradish peroxidase conjugate; IPTG: Isopropyl- $\beta$-D-thiogalactopyranoside; PMSF: Phenylmethylsulfonyl fluoride; DMSO: Dimethyl sulfoxide; FBS: Fetal bovine serum; Dab: Domain antibody library; FACS: Flow cytometric analysis; CDR: Complementarity determining region; SDS-PAGE: Sodium dodecyl sulfate polyacrylamide gel electrophoresis; PE: Phycoerythrin; HE: Hematoxylin-eosin; VEGF: Vascular endothelial growth factors; TKIs: Tyrosine kinase inhibitors; ADC: Antibody-drug conjugate.

\section{Acknowledgements}

We would like to thank the graduate students and technicians in the Cancer Therapy Group in Institute of Biomedicine of Jinan University.

\section{Authors' contributions}

HW contributed conception and design of the study. TC, XL and HH performed the experiments, analyzed the data and drafted the manuscript. All authors contributed to manuscript revision. All authors read and approved the final manuscript.

\section{Funding}

This work was supported by funds from the Science and Technology Program of Guangdong No. 2017 A020211014 (H. Wei).

\section{Availability of data and materials}

The datasets generated for this study can be found in the European Nucleotide Archive (https://www.ebi.ac.uk/ena/data/view/LR743560, https://www. ebi.ac.uk/ena/data/view/LR743561, https://www.ebi.ac.uk/ena/data/view/ LR743562, https://www.ebi.ac.uk/ena/data/view/LR743563, and https://www. ebi.ac.uk/ena/data/view/LR743564) using the accession numbers LR743560, LR743561, LR743562, LR743563 and LR743564.

\section{Ethics approval and consent to participate}

All animal experiments were performed in accordance with the protocols approved by the Institutional Animal Care and Use Committee of Jinan University.

\section{Consent for publication}

Not applicable.

\section{Competing interests}

The authors report no conflicts of interest in this work.

Received: 17 June 2020 Accepted: 21 September 2020

Published online: 06 October 2020

\section{References}

1. Chen Z, Oh D, Dubey AK, Yao M, Yang B, Groves JT, et al. EGFR family and Src family kinase interactions: mechanics matters? Curr Opin Cell Biol. 2018;51:97-102. https://doi.org/10.1016/j.ceb.2017.12.003.

2. Yarden Y, Sliwkowski MX. Untangling the ErbB signalling network. Nat Rev Mol Cell Biol. 2001;2(2):127-37. https://doi.org/10.1038/35052073.
3. Giaccone G, Wang Y. Strategies for overcoming resistance to EGFR family tyrosine kinase inhibitors. Cancer Treat Rev. 2011;37(6):456-64. https:// doi.org/10.1016/j.ctrv.2011.01.003.

4. Yamashita N, Kondo M, Zhao S, Li W, Koike K, Nemoto K, et al. Picrasidine $\mathrm{G}$ decreases viability of MDA-MB 468 EGFR-overexpressing triple-negative breast cancer cells through inhibition of EGFR/STAT3 signaling pathway. Bioorg Med Chem Lett. 2017;27(11):2608-12. https://doi.org/10.1016/j. bmcl.2017.03.061.

5. Mizukami T, Izawa N, Nakajima TE, Sunakawa Y. Targeting EGFR and RAS/ RAF signaling in the treatment of metastatic colorectal cancer: from current treatment strategies to future perspectives. Drugs. 2019;79(6):63345. https://doi.org/10.1007/s40265-019-01113-0.

6. Yu X, Li W, Deng Q, You S, Liu H, Peng S, et al. Neoalbaconol inhibits angiogenesis and tumor growth by suppressing EGFR-mediated VEGF production. Mol Carcinog. 2017;56(5):1414-26. https://doi.org/10.1002/ mc.22602.

7. Mitsudomi T, Yatabe Y. Epidermal growth factor receptor in relation to tumor development: EGFR gene and cancer. FEBS J. 2010;277(2):301-8. https://doi.org/10.1111/j.1742-4658.2009.07448.x.

8. Modest DP, Pant S, Sartore-Bianchi A. Treatment sequencing in metastatic colorectal cancer. Eur J Cancer. 2019;109:70-83. https://doi.org/10.1016/j. ejca.2018.12.019.

9. Imakita T, Matsumoto H, Hirano K, Morisawa T, Sakurai A, Kataoka Y. Impact on prognosis of rebiopsy in advanced non-small cell lung cancer patients after epidermal growth factor receptor-tyrosine kinase inhibitor treatment: a systematic review. BMC Cancer. 2019;19(1):105. https://doi. org/10.1186/s12885-019-5309-X.

10. Chanier T, Chames P. Nanobody engineering: toward next generation immunotherapies and immunoimaging of cancer. Antibodies. 2019;8(1):13. https://doi.org/10.3390/antib8010013.

11. Barton S, Starling N, Swanton C. Predictive molecular markers of response to epidermal growth factor receptor (EGFR) family-targeted therapies. Curr Cancer Drug Targets. 2010;10(8):799-812. https://doi. org/10.2174/156800910793357925.

12. Chiu ML, Goulet DR, Teplyakov A, Gilliland GL. Antibody structure and function: the basis for engineering therapeutics. Antibodies. 2019. https //doi.org/10.3390/antib8040055.

13. Khoo YL, Cheah SH, Chong H. Humanization of chimeric anti-CD2O antibody by logical and bioinformatics approach with retention of biological activity. Immunotherapy. 2017;9(7):567-77. https://doi.org/10.2217/ imt-2017-0016.

14. Bechan GI, Lee DW, Zajonc DM, Heckel D, Xian R, Throsby M, et al. Phage display generation of a novel human anti-CD1A monoclonal antibody with potent cytolytic activity. Br J Haematol. 2012;159(3):299-310. https:// doi.org/10.1111/bjh.12033.

15. Chen Y, Liu G, Guo L, Wang H, Fu Y, Luo Y. Enhancement of tumor uptake and therapeutic efficacy of EGFR-targeted antibody cetuximab and antibody-drug conjugates by cholesterol sequestration. Int J Cancer. 2015;136(1):182-94. https://doi.org/10.1002/ij..28950.

16. Niesen J, Hehmann-Titt G, Woitok M, Fendel R, Barth S, Fischer R, et al. A novel fully-human cytolytic fusion protein based on granzyme B shows in vitro cytotoxicity and ex vivo binding to solid tumors overexpressing the epidermal growth factor receptor. Cancer Lett. 2016;374(2):229-40. https://doi.org/10.1016/j.canlet.2016.02.020.

17. Deng HK, Zhou J, Gong BB, Xiao M, Zhang M, Pang Q, et al. Screening and identification of a human domain antibody against Brucella abortus VirB5. Acta Trop. 2019. https://doi.org/10.1016/j.actatropica.2019.05.017.

18. Fouladi M, Sarhadi S, Tohidkia M, Fahimi F, Samadi N, Sadeghi J, et al. Selection of a fully human single domain antibody specific to 
Helicobacter pylori urease. Appl Microbiol Biotechnol. 2019;103(8):340720. https://doi.org/10.1007/s00253-019-09674-6.

19. Hairul Bahara NH, Chin ST, Choong YS, Lim TS. Construction of a semisynthetic human VH single-domain antibody library and selection of domain antibodies against alpha-crystalline of Mycobacterium tuberculosis. J Biomol Screen. 2016;21(1):35-43. https://doi.org/10.1177/1087057115 609144.

20. Wang H, Wang Y, Xiao Z, Li W, Dimitrov DS, Chen W. Human domain antibodies to conserved epitopes on HER2 potently inhibit growth of HER2-overexpressing human breast cancer cells in vitro. Antibodies. 2019;8(1):25. https://doi.org/10.3390/antib8010025.

21. Nilvebrant J, Tessier MP, Sidhu SS. Engineered autonomous human variable domains. Curr Pharm Des. 2016;22(43):6527-37. https://doi org/10.2174/1381612822666160921143011.

22. Henry KA, Tanha J. Performance evaluation of phage-displayed synthetic human single-domain antibody libraries: a retrospective analysis. J Immunol Methods. 2018;456:81-6. https://doi.org/10.1016/j.jim.2018.02.009.

23. Ha KD, Bidlingmaier SM, Zhang Y, Su Y, Liu B. High-content analysis of antibody phage-display library selection outputs identifies tumor selective macropinocytosis-dependent rapidly internalizing antibodies. Mol Cell Proteomics. 2014;13(12):3320-31. https://doi.org/10.1074/mcp. M114.039768.

24. Sha H, Zou Z, Xin K, Bian X, Cai X, Lu W, et al. Tumor-penetrating peptide fused EGFR single-domain antibody enhances cancer drug penetration into 3D multicellular spheroids and facilitates effective gastric cancer therapy. J Control Release. 2015;200:188-200. https://doi.org/10.1016/j. jconrel.2014.12.039.

25. Khawar IA, Kim JH, Kuh H-J. Improving drug delivery to solid tumors: priming the tumor microenvironment. J Control Release. 2015;201:78-89. https://doi.org/10.1016/j.jconrel.2014.12.018.

26. Catapano AL, Papadopoulos N. The safety of therapeutic monoclonal antibodies: implications for cardiovascular disease and targeting the PCSK9 pathway. Atherosclerosis. 2013;228(1):18-28. https://doi. org/10.1016/j.atherosclerosis.2013.01.044.

27. Pawar A, Prabhu P. Nanosoldiers: a promising strategy to combat triple negative breast cancer. Biomed Pharmacother. 2019;1 10:319-41. https:// doi.org/10.1016/j.biopha.2018.11.122.

28. Zhang F, Wang S, Yin L, Yang Y, Guan Y, Wang W, et al. Quantification of epidermal growth factor receptor expression level and binding kinetics on cell surfaces by surface plasmon resonance imaging. Anal Chem. 2015;87(19):9960-5. https://doi.org/10.1021/acs.analchem.5b02572.

29. Fozing T, Scheuer C, Samnick S. Synthesis and initial tumor affinity testing of iodine-123 labelled EGFR-affine agents as potential imaging probes for hormone-refractory prostate cancer. Eur J Med Chem. 2010;45(9):3780-6. https://doi.org/10.1016/j.ejmech.2010.05.027.
30. De Robertis M, Loiacono L, Fusilli C, Poeta ML, Mazza T, Sanchez M, et al. Dysregulation of EGFR pathway in EphA2 cell subpopulation significantly associates with poor prognosis in colorectal cancer. Clin Cancer Res. 2017;23(1):159-70. https://doi.org/10.1158/1078-0432.CCR-16-0709.

31. Sigismund $S$, Avanzato $D$, Lanzetti L. Emerging functions of the EGFR in cancer. Mol Oncol. 2018;12(1):3-20. https://doi.org/10.1002/18780261.12155.

32. Yang $Y$, Zhou W, Wu J, Yao L, Xue L, Zhang Q, et al. Antitumor activity of nimotuzumab in combination with cisplatin in lung cancer cell line A549 in vitro. Oncol Lett. 2018;15(4):5280-4. https://doi.org/10.3892/ ol.2018.7923.

33. Lim Y, Yoo J, Kim MS, Hur M, Lee EH, Hur HS, et al. GC1118, an anti-EGFR antibody with a distinct binding epitope and superior inhibitory activity against high-affinity EGFR ligands. Mol Cancer Ther. 2016;15(2):251-63. https://doi.org/10.1158/1535-7163.MCT-15-0679.

34. Voigt M, Braig F, Gothel M, Schulte A, Lamszus K, Bokemeyer C, et al. Functional dissection of the epidermal growth factor receptor epitopes targeted by panitumumab and cetuximab. Neoplasia. 2012;14(11):102331. https://doi.org/10.1593/neo.121242.

35. Birnbaum ME, Berry R, Hsiao Y-S, Chen Z, Shingu-Vazquez MA, Yu X, et al. Molecular architecture of the $a \beta$ T cell receptor-CD3 complex. Proc Natl Acad Sci USA. 2014;111(49):17576-81. https://doi.org/10.1073/ pnas. 1420936111.

36. Orian-Rousseau V, Ponta H. Perspectives of CD44 targeting therapies. Arch Toxicol. 2015;89(1):3-14. https://doi.org/10.1007/s00204-014-1424-2.

37. Martin C, Kizlik-Masson C, Pelegrin A, Watier H, Viaud-Massuard MC, Joubert N. Antibody-drug conjugates: design and development for therapy and imaging in and beyond cancer, LabEx MAbImprove industrial workshop, July 27-28, 2017, Tours, France. MAbs. 2018;10(2):210-21. https ://doi.org/10.1080/19420862.2017.1412130.

38. Tian B, Wong WY, Hegmann E, Gaspar K, Kumar P, Chao H. Production and characterization of a camelid single domain antibody-urease enzyme conjugate for the treatment of cancer. Bioconj Chem. 2015;26(6):114455. https://doi.org/10.1021/acs.bioconjchem.5b00237.

39. Sugahara KN, Teesalu T, Karmali PP, Kotamraju VR, Agemy L, Greenwald $\mathrm{DR}$, et al. Coadministration of a tumor-penetrating peptide enhances the efficacy of cancer drugs. Science. 2010;328(5981):1031-5. https://doi. org/10.1126/science.1183057.

\section{Publisher's Note}

Springer Nature remains neutral with regard to jurisdictional claims in published maps and institutional affiliations.
Ready to submit your research? Choose BMC and benefit from:

- fast, convenient online submission

- thorough peer review by experienced researchers in your field

- rapid publication on acceptance

- support for research data, including large and complex data types

- gold Open Access which fosters wider collaboration and increased citations

- maximum visibility for your research: over $100 \mathrm{M}$ website views per year

At BMC, research is always in progress.

Learn more biomedcentral.com/submissions 